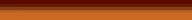

\author{
Research
}

ISSN: 1522-8053 (Print) 2333-6897 (Online) Journal homepage: https://www.tandfonline.com/loi/utca20

\section{Analyzing R\&D Knowledge Flows In The Flat World}

\author{
Eoin Whelan, Brian Donnellan \& Willie Golden
}

To cite this article: Eoin Whelan, Brian Donnellan \& Willie Golden (2009) Analyzing R\&D Knowledge Flows In The Flat World, Journal of Information Technology Case and Application Research, 11:2, 12-30, DOI: 10.1080/15228053.2009.10856157

To link to this article: https://doi.org/10.1080/15228053.2009.10856157

\section{曲 Published online: 12 Sep 2014.}

Submit your article to this journal 준

Шll Article views: 20

4 Citing articles: 3 View citing articles 


\title{
ANALYZING R\&D KNOWLEDGE FLOWS IN THE FLAT WORLD
}

\author{
Eoin Whelan \\ University of Limerick, Ireland \\ eoin.whelan@ul.ie
}

Brian Donnellan and Willie Golden

National University of Galway, Ireland

\begin{abstract}
Previous research has firmly established the importance of informal social networks in facilitating knowledge flows in research and development (R\&D) settings. However, the explosion of Web technologies in recent years have 'flattened' the planet and dramatically altered our understanding of what constitutes a social network. Despite this, current research has neglected to examine how Web technologies have impacted knowledge flows in $R \& D$. To address this research gap, we revisit the highly influential technological gatekeeper theory. Drawing on social network analysis (SNA) and interview evidence from a medical devices $R \& D$ group, we find that the gatekeeper role is still vital, but no longer needs to be performed by a single individual. Instead, the modern $R \& D$ group can keep abreast of the latest technological advances through a combination of Web-enabled internal and external communication specialists. A unique contribution this paper makes to the IT-enabled social network literature is the development of an updated conceptual framework of how the gatekeeper role is performed in the modern $R \& D$ group.
\end{abstract}

Keywords: Social networks, Knowledge management, Technological gatekeeper, Web technologies, $R \& D$.

\section{INTRODUCTION}

In today's rapidly changing business environment, few firms can afford to remain completely self-sustaining. For firms competing on knowledge and the ability to innovate and adapt, it is essential that they keep abreast of the latest scientific and technological developments. Increasingly, this knowledge is dispersed outside the firm's boundaries (Chesbrough, 2003). How does this external knowledge which is critical to success get integrated into the firm? A large body of literature exists which highlights the importance which informal social networks play in transferring knowledge within and between organizations (Allen \& Cohen 1969; Allen 1977; Hansen 1999; Wenger, McDermott et al. 2002; Assimakopoulos \& Macdonald 2003; Wasko \& Faraj 2005; Su, Mark et al. 2007). However, the explosion of Web technologies in recent years has dramatically altered our understanding of what constitutes a social network. A person can be a member of many social networks ranging from face-to-face interactions with close personal friends to Web-based collaborations with globally dispersed unknown and anonymous colleagues. Research is needed to inform organizations how business value can be generated from 
the interplay between the social and technical aspects of these socio-technical systems (Parameswaran \& Whinston 2007).

Using the theoretical lens of the technological gatekeeper (Allen 1977), the purpose of this paper is to address this research gap by examining how external knowledge of the latest scientific and technological developments diffuses in the research and development (R\&D) group - a practicebased social network vital to the success of high technology firms. Drawing on social network analysis (SNA) and interview evidence from a medical devices R\&D group, we find that Web technologies have impacted the gatekeeper role to the extent that it no longer needs to be performed by a single individual. Based on our findings, we present an updated conceptual framework of how the gatekeeper role is now performed in the modern R\&D group.

The paper is divided into six additional sections. The following section reviews the seminal technological gatekeeper literature. We then operationalize our meaning of Web technologies and develop the research question to be addressed. The data collection methods adopted are considered next, along with a description of the case study site. The findings of the SNA and semi-structured interviews are then presented, followed by a discussion of these findings and the presentation of our conceptual framework. Finally, we conclude with the implications of our findings on research and practice relating to organizational knowledge and learning.

\section{THE TECHNOLOGICAL GATEKEEPER}

R\&D groups are the drivers of innovation in high-technology firms. In order for the group to sustain itself, the literature on R\&D innovation emphasizes the importance of acquiring a diverse and novel body of knowledge from beyond the organizational boundaries (Allen 1977; Tushman 1977; Aldrich \& Herker 1997; Chesbrough 2003). The acquisition of external R\&D knowledge helps the firm to build its 'absorptive capacity' (Cohen \& Levinthal 1990) and will serve as the seeds for future technological developments (March \& Simon 1958; Leonard-Barton 1992). A rich stream of research throughout the 1970's and early 1980's examined the processes through which scientific and technological knowledge enters the R\&D group. This particular stream was headed by MIT's Thomas Allen and his seminal book Managing the Flow of Technology (Allen 1977) documents over a decades worth of studies with some of the largest American R\&D corporations. Allen discovered that knowledge of the latest scientific and technological developments entered the R\&D group through a two-step process. Not every R\&D professional was directly connected with external sources of knowledge. Instead, a small minority had rather extensive contacts and served as sources of knowledge for their colleagues. These individuals are termed 'technological gatekeepers' (Allen \& Cohen 1969; Allen 1971; Allen 1977; Tushman 1977; Allen, Tushman et al. 1979; Katz \& Tushman 1981; Tushman \& Scanlan 1981; Harada 2003 ) as they act as the conduit through which knowledge of external technology flows into the R\&D group. A more formal definition explains that technological gatekeepers are those key individual technologists who are strongly connected to both internal colleagues and external sources of knowledge, and who possess the ability to translate between the two systems (Allen \& Cohen 1969; Allen 1977; Tushman \& Scanlan 1981). The gatekeeper concept is consistent with other theories of social diffusion, such as diffusion of innovations (Rogers 1962; Rogers 1995), strength of weak ties (Granovetter 1973), structural holes (Burt 1992), and social epidemics (Gladwell 2000), which all point towards the crucial role a small number of exceptional people 
play in spreading valuable information, trends, and ideas. The pattern of communication between the average R\&D professional and the world beyond the firm's boundaries is illustrated in Figure 1 .

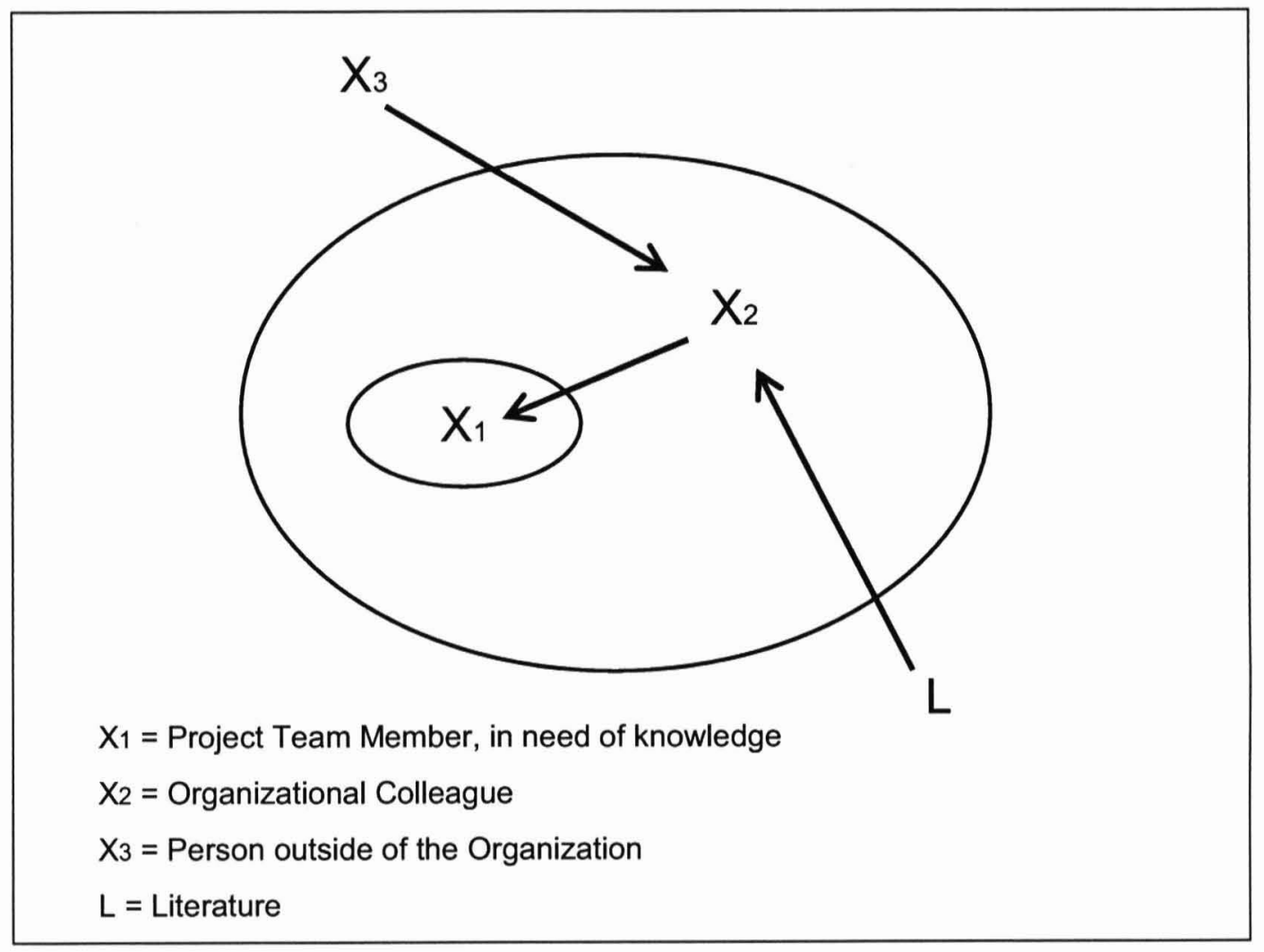

Figure 1: The Two-step Flow of Technological Knowledge (Adapted from Allen 1977)

Allen and Cohen $(1969$, p. 16) noted when studying gatekeepers in the R\&D division of a large aerospace firm that "...if one were to sit down and attempt to design an optimal system for bringing in new technological information and disseminating it within the organization, it would be difficult to produce a better one than that which exists." Indeed, subsequent studies have provided the empirical evidence to support this claim. Development focused R\&D projects containing gatekeepers have been found to be significantly higher performing than those without (Tushman \& Katz 1980; Katz \& Tushman 1981). Gatekeepers perform three tasks that make them critical to the R\&D knowledge flow network. Firstly, they perform the task of external knowledge acquisition. Gatekeepers act as the firm's antennae, scanning the outside world for emerging scientific and technological developments relevant to the work of their R\&D group. They tend to read the harder-literature (e.g. scientific journals), present more papers at technical conferences, and maintain long-term relationships with colleagues outside their own organization. Through these external connections, they tend to have their finger on the pulse of industry developments and can import this knowledge back into the R\&D group. Secondly, they perform the task of external knowledge translation. The gatekeeper can convert knowledge gained from JITCAR Volume 11, Number 2, 2009 
journal papers and personal contacts into terms that are understandable and relevant to local R\&D colleagues. This task is needed due to the evolution of local norms, values and languages tailored to the requirements of the group's work (Tushman 1977). The local coding scheme that evolves becomes unique and largely different to the coding schemes used beyond the organization's boundaries. The gatekeeper's principle contribution comes by way of the translation that they can perform between the two systems (Allen 1977). Thirdly, gatekeepers perform the task of external knowledge dissemination. Although gatekeepers may well have their own use for the knowledge they acquire, they are also keenly interested in passing it on to others in the organization for their use (Macdonald \& Williams 1994). They are familiar with the internal communication networks of the organization. Indeed, they are as dedicated to exploiting this familiarity as they are to acquiring knowledge from outside the organization.

The gatekeeper requires certain characteristics that enable them to acquire, translate, and disseminate external knowledge. Not every person possesses these characteristics, hence the reason only a handful of individuals can effectively perform the gatekeeper role. The original studies of Allen and Cohen (1969) and Allen (1977) suggest that the gatekeeper is a highly competent technical performer who is likely to be a first line supervisor. Seldom are gatekeepers found with fewer than five years organizational experience as it takes time to develop one's communication network. A significant characteristic of the gatekeeper is their social networking abilities. Previous studies have shown that oral communications and not written materials are considered the primary medium through which R\&D professionals import and digest technical information within the organization (Allen 1977; De Meyer 1985; Macdonald \& Williams 1994). By extension, gatekeepers tend to be highly sociable and people-orientated individuals who can acquire and disseminate knowledge orally. Indeed, it has been found that attempts by management to formally appoint employees to perform the gatekeeping role have proved unsuccessful, primarily because appointed individuals lack the social networking skills of the organic gatekeeper (Nochur \& Allen 1992).

\section{DEVELOPING THE RESEARCH QUESTION}

The gatekeeper concept has received modest attention since the mid 1980's. In recent years however, some interest in the concept has been reignited, particularly in the IS field. The gatekeeper existed in a time when it was a difficult and time-consuming process for the average R\&D professional to acquire knowledge from beyond the company's boundaries. The past decade has borne witness to major advances in information and communication technologies and particularly Web technologies. What these advances have changed is the ease and speed with which employees at all organizational levels can access and disseminate knowledge (Teigland \& Wasko 2003; Whelan 2007). With a PC and an Internet connection, a knowledge worker can join computer-supported social networks to seek solutions, share expertise, and discuss ideas with like-minded individuals far beyond the reach of their local social network of friends, contacts, and colleagues (Wasko, Faraj et al. 2004). As argued by Thomas Friedman in his best selling book, the emergence of Web technologies has considerably 'flattened' the world (Friedman 2006). However, scant attention has been paid to how these advances in communication technologies have impacted the role of the gatekeeper. 
Some recent studies have questioned the role of the gatekeeper in the modern R\&D group. Research by Harada (2003) reports that the members of a Japanese machine tool firm who are highly connected to external knowledge sources are largely different to those members of the firm who are highly connected internally. From this finding, Harada infers that external knowledge becomes integrated into the $\mathrm{R} \& \mathrm{D}$ group through a multi-step process whereby external communication stars pass the outside knowledge they acquire to the internal communication stars, who in turn transmit to other members of the firm. However, we believe this inference remains open to question as Harada's study relies exclusively on statistical measures of communication. Statistical measures may point towards a certain sequence, but these measures alone are insufficient to demonstrate that such a sequence is reality. A unique contribution which our paper makes is the use of both statistical (SNA) and qualitative (semi-structured interviews) methods to explore how external knowledge flows into and around the R\&D group. Additionally, Assimakopoulos \& Yan (2006) find that online forums facilitate software engineers in the exchange of technical knowledge across organizational boundaries. They conclude that such technologies may mitigate the role of the technological gatekeeper in the innovation process. We empirically address Assimakopoulos and Yan's argument and ask the research question: How have Web technologies impacted the technological gatekeeper's tasks of acquiring, translating, and disseminating external knowledge?

We have specifically chosen to examine the impact of Web technologies as an earlier pilot study by the authors (Whelan \& Donnellan, 2008) found that the key communication technologies used by $R \& D$ engineers to acquire and distribute technological information were websites, search engines, and email. Hence, our definition of Web technologies centers on these applications. For the purposes of this study, we define Web technologies as "Web-based communication technologies, such as websites, search engines, and email that enable the easy exchange and retrieval of digitized content."

\section{RESEARCH METHODS}

\section{Case Study Setting}

This study was carried out at the R\&D division of a medium-sized Irish medical devices firm. This firm designs and develops technologies and products that assist medical device manufacturers improve outcomes for patients. The R\&D group primarily provides design and development expertise for medical device companies who wish to outsource their device design. The group's core competence is in the area of catheter-based minimally invasive devices. The group numbers 42 in total, mostly consisting of design and mechanical engineers. The new product development work performed by this group involves identifying existing and emerging technologies and applying these to solve particular technical problems. This site was specifically chosen because of its resemblance to the sites studied by the original gatekeeper research, which tended to be development focused R\&D groups of high-technology engineering firms. Indeed, previous gatekeeper studies have also gathered data from medical device firms (Tushman \& Scanlan 1981).

\section{Data Collection and Analysis}

Case study data was gathered during the months of October and November 2007 and consisted of two phases. Phase 1 involved analyzing the flow of knowledge into and around the R\&D group 
using SNA techniques. The purpose of this phase was to identify the 'stars' of the knowledge flow network. To collect this data, all 42 group members were asked to complete a short online questionnaire which sought responses on their level of internal and external communications. To measure internal communications, each respondent was asked to identify which of their work colleagues they discussed technical issues with at least once a week. This exact question was also used by the original gatekeeper scholars. The choice of once-a-week frequency is purely arbitrary, although it does represent a fairly heavy degree of consistent communication (Allen 1977). Our initial pilot study and preliminary discussions with the group's R\&D manager confirmed that the term 'technical issues' was appropriate for capturing the valuable information group members needed to perform their work. To measure external communications, respondents were asked to indicate how often they used three sources of external knowledge; academic publications, contacts outside the organization that you know personally (including face-to-face, phone, and email contacts), and the Web (other than accessing journal papers i.e. websites, discussion forums, wikis, blogs). The earlier pilot study indicated that these three knowledge sources were the most frequently used by $R \& D$ professionals when acquiring knowledge from outside the company. The questionnaire also included an open-ended question allowing respondents to indicate any other sources of external knowledge they use. 38 completed questionnaires were received giving a response rate of $90 \%$. A particular SNA software package called UCINET (Borgatti, Everett et al. 2002) was used to visually illustrate the knowledge flow network (see Figure 2). To increase validity, only reciprocated interactions between group members were included in the analysis. This ensured that group members who reported higher than actual interactions did not distort the analysis.

In phase 2, 10 semi-structured interviews with selected group members were conducted. The objective of the interviews was to explore how the use of Web technologies impacts the acquisition, translation, and dissemination functions of the technological gatekeeper (see the Appendix for examples of the interview questions asked). The interviewees were selected based on the SNA results from phase 1. Every group member was categorized as being a gatekeeper, an internal communication star, an external communication star, or a non-star. Following the approach of (Allen 1977; Tushman \& Katz 1980; Katz \& Tushman 1981), this study operationalized gatekeepers as those individuals who were in the top fifth of both the internal and external communication distributions. Internal stars were operationalized as those individuals in the top fifth of the internal communication distribution but outside the top fifth of the external communication distribution. The reverse applies for external stars. While we acknowledge that the use of cut-off frequencies is an arbitrary measure which may lead to imprecise interpretations, it serves our purpose of identifying the key individuals in the R\&D knowledge flow network. Indeed, we use the evidence generated from the qualitative interviews to test our interpretation of the SNA evidence. To get a non-biased view of how knowledge flowed around the group, we interviewed 2 gatekeepers, 2 external stars, 2 internal stars, and 4 non-stars. Care was also taken to ensure that all levels of the formal group hierarchy were represented in the interviewee sample. All interviews were conducted face-to-face and ranged in length from 30 minutes to 75 minutes. In addition, all interviewees gave permission for the interview to be recorded. The procedures outlined in the dramaturgical model (Myers \& Newman 2007) were adopted in order to ensure that high-quality interviews were conducted. Interview data analysis was performed using the 
NVivo software package and followed established inductive qualitative methods: coding, data categorization, and pattern identification (Miles \& Huberman 1984; Eisenhardt 1989; Yin 1994).

\section{FINDINGS}

\section{Phase 1: Social Network Analysis}

Figure 2 illustrates the flow of technical knowledge into and around the R\&D group. The nodes in the diagram are the individual members of the group and the lines represent the flow of technical knowledge between them. The more connected nodes tend to gravitate towards the centre of the network while those nodes with fewer connections are found on the periphery. The external stars are represented as triangles. The size of the triangle is reflective of how well connected that individual is to external knowledge sources. Node 9 is the biggest triangle as this individual is the most frequent user of external knowledge sources. Nodes 4, 16, 35 and 40 did not complete the questionnaire, hence the reason they are isolated on the left. Nodes 2, 11, 38 and 42 are in the same position because they have no reciprocated interactions with another group member.

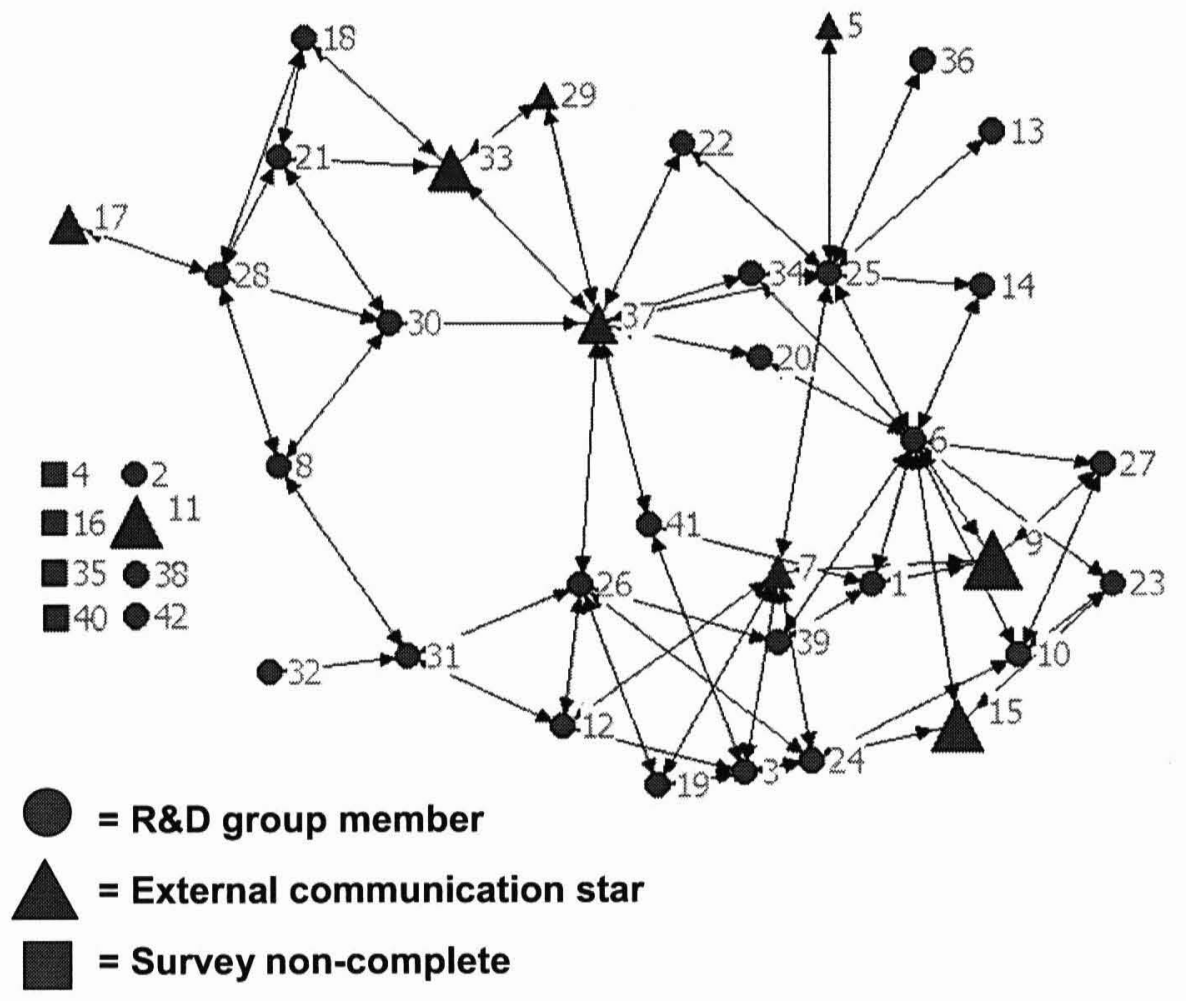

Figure 2: The R\&D Knowledge Flow Network 
Figure 2 reveals a number of key people in group's knowledge flow network. Firstly, there are nodes 7 and 37. Using the classic definition, only these two members (or 5\%) of the group can be classified as technological gatekeepers. While external knowledge is imported and disseminated around the group by these two gatekeepers, the SNA evidence indicates that separate communication specialists also combine to perform the gatekeeping role. One set of boundary spanning individuals acquire external knowledge, and a largely different set of individuals distribute this knowledge around the group. The relationship between node 5 and node 25 can be used to demonstrate this process (the relationship between nodes 17 and 28 , nodes 9 and 6 , or nodes 15 and 6 could also have been used). Node 5 is an external communication star. This individual is well connected to external knowledge sources but is not very well connected internally. Node 5 acquires external knowledge and communicates this to node 25 . Node 25 , on the other hand, is well connected internally and can distribute this knowledge around the group through his or her many connections. It must be noted however that the SNA evidence, and our interpretation of that evidence, only suggests that such a sequence of knowledge flow is evident. Semi-structured interviews with selected group members were also conducted to validate this interpretation, and to explore the impact of Web technologies.

An analysis of the frequency of use of the three external knowledge sources reveals a vastly wide range existing between group members. Some group members are highly exposed to external sources while others rarely seek knowledge from beyond the company's boundaries. Figure 3 contrasts the external communication stars with the rest of the group. The Web was the most widely used source with $89 \%$ of external stars using this knowledge source at least once a day. $67 \%$ of external stars reported consulting a personal external contact while only $22 \%$ would read journal papers on a daily basis. The Web was the most frequently used source of external knowledge by the remaining group members albeit at a vastly lower frequency. In contrast to the external stars, only $10 \%$ of the remaining group used the Web as a knowledge source on a daily basis. 3\% consulted with external contacts while none of the remaining group reported reading journal papers at least once a day.

Question 4 of the SNA survey was an open-ended question and asked respondents to identify sources outside the group who are important in terms of providing them with the information to do their work. Regarding external contacts, most respondents identified a particular person in a supplier firm. Members of the engineering faculty at the local university were also identified, but to a far lesser extent to suppliers. A number of websites were identified as well. The Google suite of products were frequently mentioned, particularly the search engine and Google Groups dedicated to product design. Interestingly, a small number of respondents named wikipedia as being an important source for their work. In addition, members of the R\&D group frequently used the material properties website matweb.com. As this website explains, it has over 69,000 materials in its database which is continually being updated by manufacturers. The database can be easily searched allowing engineers to identify the latest advances in metals, plastics, ceramics, and composites. 


\section{$\%$ who use at least once a day}

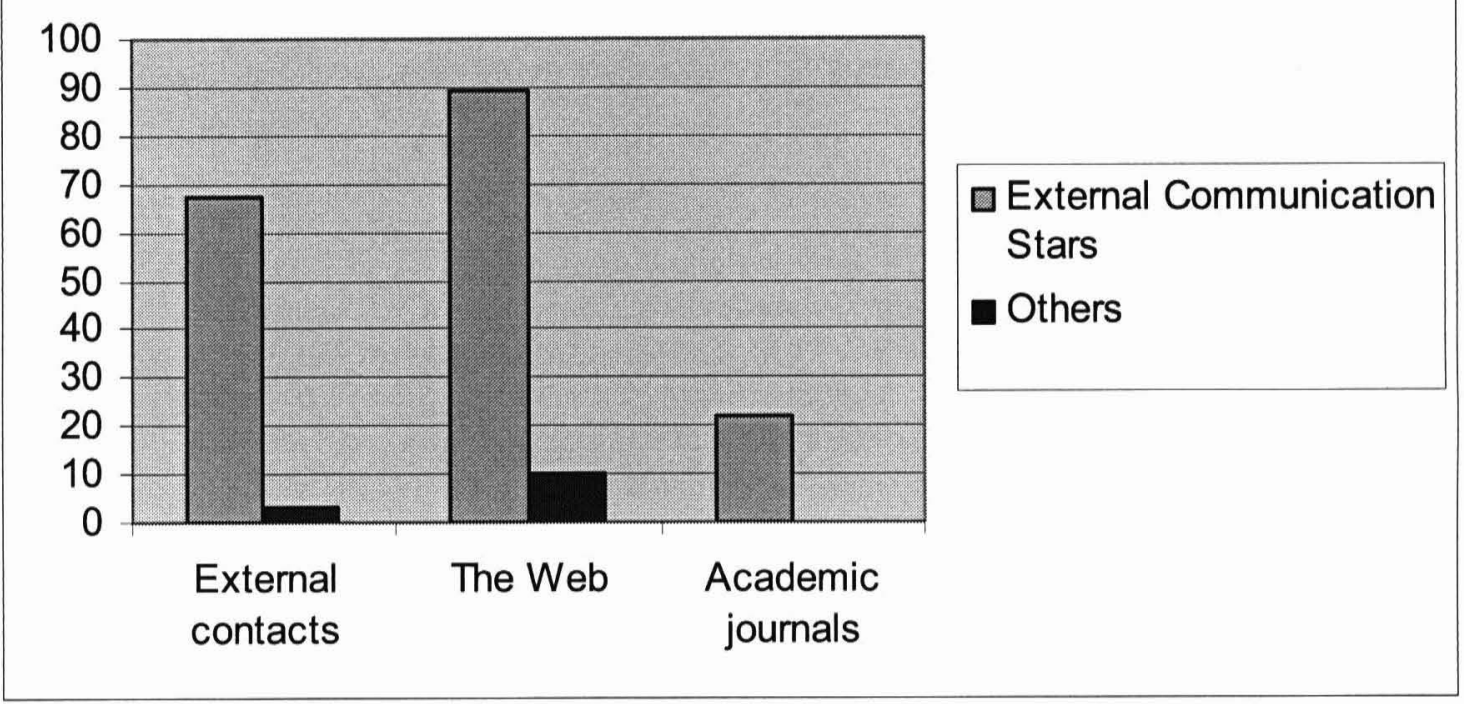

Figure 3: External Knowledge Sources Used

\section{Phase 2: Semi Structured Interviews}

We interpreted the SNA evidence to purport that the gatekeeping function is performed either by single individuals - the gatekeepers themselves - or more likely by a combination of external and internal communication specialists. The interview evidence (summarized in Table 1) largely supports our interpretation of the SNA evidence. The external communication stars are largely responsible for acquiring novel external knowledge while a different set of individuals, the internal communication stars, perform both the knowledge translation and dissemination tasks.

Under the headings of the three gatekeeper tasks, we now provide some exemplar quotes from the interviews. The 'external knowledge acquisition' findings are based on the interviews with the external stars, while the 'external knowledge translation' and 'external knowledge dissemination' findings are taken from the internal star interviews. The evidence gathered from the gatekeepers as to their operations is also contrasted with those of the communication stars.

External Knowledge Acquisition: The interviews explored the key knowledge sources used by the group, and particularly the external stars, to acquire external technological knowledge. The SNA data in phase 1 showed the Web to be the most widely used channel for accessing external knowledge sources. The interviews indicated that it was also the most valuable. The Web is a relatively new invention and it has only been in the past few years that the use of this technology has become prevalent. Web technologies are now vital to the group's daily work as is illustrated in the following quotation from the R\&D manager: 
The Internet is probably the most important tool we have in our industry and definitely the most widely used. Trade shows and subscription to general papers are useful but you can find an awful lot when you just do a Google search.

Knowledge of the latest technological developments in the field is vital to the success of the R\&D group. As the group contracts its R\&D services to corporate customers, it is necessary to demonstrate that the group is working with and developing the cutting edge technologies in the

\begin{tabular}{|c|c|c|c|}
\hline & Ability & Motivation & Medium Used \\
\hline $\begin{array}{l}\text { External } \\
\text { Communication } \\
\text { Stars }\end{array}$ & $\begin{array}{l}\text { - Acquire relevant } \\
\text { knowledge of external } \\
\text { developments } \\
\text { - Narrow and deep } \\
\text { technology domain } \\
\text { - Strong analytical skills }\end{array}$ & $\begin{array}{l}\text { - Genuine interest in } \\
\text { keeping abreast of } \\
\text { emerging trends in } \\
\text { their specialty } \\
\text { - Primarily acquire } \\
\text { knowledge for } \\
\text { own use but lack } \\
\text { the skills to } \\
\text { disseminate } \\
\text { effectively }\end{array}$ & $\begin{array}{l}\text {-Predominately } \\
\text { Web-based e.g. } \\
\text { Google search, } \\
\text { online } \\
\text { communities, } \\
\text { materials } \\
\text { websites }\end{array}$ \\
\hline $\begin{array}{l}\text { Internal } \\
\text { Communication } \\
\text { Stars }\end{array}$ & $\begin{array}{l}\text { - Can translate external } \\
\text { knowledge into a form } \\
\text { understandable and } \\
\text { relevant to internal } \\
\text { colleagues } \\
\text { - Verify that Web-based } \\
\text { information is accurate } \\
\text { and reliable } \\
\text { - Act like the Golden } \\
\text { Pages, know where the } \\
\text { expertise resides } \\
\text { internally }\end{array}$ & $\begin{array}{l}\text { - Enjoy helping } \\
\text { others } \\
\text { - Own knowledge } \\
\text { grows from these } \\
\text { interactions } \\
\text { - Expect } \\
\text { reciprocation }\end{array}$ & -Email and oral \\
\hline Gatekeepers & $\begin{array}{l}\text { - Same as external and } \\
\text { internal communication } \\
\text { stars } \\
\text { - Highly sociable with very } \\
\text { good networking skills } \\
\text { enabling them to } \\
\text { develop extensive } \\
\text { internal and external } \\
\text { networks } \\
\text {-Eliciting information } \\
\text { from people in oral } \\
\text { conversations }\end{array}$ & $\begin{array}{l}\text { May acquire } \\
\text { knowledge for } \\
\text { their own use but } \\
\text { also transmit it } \\
\text { others } \\
\text { - Enjoy helping } \\
\text { others }\end{array}$ & $\begin{array}{l}\text { - External - both } \\
\text { Web-based and } \\
\text { oral } \\
\text {-Internal - Email } \\
\text { and oral }\end{array}$ \\
\hline
\end{tabular}

Table 1: Summary Table of those Performing the Gatekeeping Role 
medical devices field. We initially expected to find that all group members would be well connected to external knowledge sources, given the ease with which this can be done through the Web. However, as Figure 3 in the previous section shows, this is not the case. No particular individual or group of individuals are formally appointed to a technology scouting role; the process occurs more organically and is driven by the external communication stars. Reflecting on how the group maintains awareness of industry developments, one external star offered his opinions and explained that some people just have a genuine interest in keeping abreast of the latest industry developments, while others:

...could walk into a room wallpapered with valuable information about the most cutting-edge technologies in our field...but if they are not interested, then they won't even notice.

The interviews attempted to elicit specific examples of how information obtained from the Web was exploited in the group's product development process. The external stars provided examples of specific new materials and molding techniques identified through the Web which were eventually integrated internally. When the external stars want to find out 'what's new,' usually the Google search engine is their first destination. Indeed, it would seem that the advances that Google have made in search have contributed to the decline of the gatekeeper. As is evidenced in the following quote, only basic IT skills are needed to locate outside knowledge sources. This external star recalls an instance where Google Images provided an unlikely solution:

We were trying to design a handle for a shaft that would be fitted to a catheter. We had a brainstorming session but we just couldn't come up with a solution. We decided to type a couple of key words from the design idea into Google Images and see what results we got back. In all, it threw up images of around 10 different devices...one in particular that used the same design we were after. That device was a ball point pen... and we ended up using a similar shaft design to the pen for our device. We would never have thought of that otherwise. It worked perfectly as it turned out.

The external stars acknowledged that much of the useful information they need for their job is available on the Web. However, even with the advances of Google, finding the exact information they want on the Web can be difficult. A Google search for any topic will return thousands of Web pages, the vast majority of which are not relevant. The interview data suggested that certain individuals exist who are particularly skilled at finding very specific and relevant information on the Web. This case study only hints at the existence of these individuals who maybe a specific type of external communication star. We have termed these individuals 'advanced search agents.' It seems that the advanced search agent possesses an intimate knowledge of where and how certain information can be found on the Web - a human search engine of sorts. The following quote from a project leader emphasizes the important role which advanced search agents play. The team was assigned a new project involving a technology they had little prior experience in:

We had a project on gammo-induction. We knew it wasn't going to be great for us... and this person went off and they came back in half a day and had reams of information...some people are just really good at finding stuff out on the Net, [whereas] some people would just type in gammo-induction and print off the first page they find. 
There's two people I have, if you want to find something out...they'll find it out and it will all be off the Net.

The results from the SNA also showed that the external stars frequently consulted with personal contacts outside the company. The interviews sought to understand whether there was a difference in the information sought from the Web when compared to personal contacts. The external stars agreed that both sources were useful when they needed to know the emerging technological trends in the industry, however, it seemed that they had a preference for using the Web to source this particular knowledge. In the opinion of one external star, the Web and specifically Google provides a better channel in terms of exploring for new developments:

We've established good relationships with a lot of suppliers for particular items and they're our go-to people, and they've become our go-to people by good performance. But for exploring what's new out there, outside the box stuff, I basically Google.

The interviews also explored the differences between the external stars and the gatekeepers. In contrast to the external stars, the gatekeepers seem to have a slight preference for acquiring external knowledge through oral conversations with outside colleagues. The gatekeepers have many contacts outside the company and they phone these on a regular basis. Certain social skills are needed to develop this network of contacts and to extract knowledge from them. The two gatekeepers interviewed were indeed quite sociable, open, and friendly in the interview setting. These social skills do not come naturally to most engineers in the group and this maybe is one reason why the Web is the preferred source of external knowledge for others. Such high social skills are not needed to extract information from the Web. An example of the social skills needed to extract knowledge from others is provided in the following interview excerpt with one gatekeeper:

The guys in the tool workshop are a great source of ideas for me...but if you need to know something, it's no good sending these guys an email. They will only help you out if they think you are a peer. There's no point going down to these guys wearing a threepiece suit...if the tool guys don't see you as a peer or with a bit of dirt on you then the answer you will get from them will be different and probably not as helpful. I would say that most people in [the R\&D group] are weary about going down to the tool workshop. You just have to know how to deal with them.

External Knowledge Translation: The external communication stars interviewed explained that they primarily acquire external knowledge for their own use, but if they come across information that would be useful to others, they would try to distribute it. However, external communication stars are not effective disseminators of knowledge as they seem to be lacking the necessary skills. To be useful to the R\&D group, the knowledge acquired from outside sources needs to be translated into a form that is understandable and relevant to group members. This is a specific skill that is most likely to be found in the group's internal communication stars, hence it is these individuals that tend to disseminate the knowledge acquired by the external stars around the group. The interviews revealed that email is the primary system used to alert colleagues to new information from outside the company. This information is usually in the form of a Web link or an attached document. While many emails are disseminated around the group containing information on current industry developments, many interviewees pointed out that only a fraction 
of these are given any attention. Two factors determine if the information contained in an email will actually be read and used further: (1) how the information in the email is presented i.e. translated so that it is relevant and understandable to the receiver, and (2) the sender of the email. Regarding the sender of information, certain members of the group have a reputation for blasting out non-relevant information to the rest of the group. One of the group's internal communication stars refers to these individuals as 'email jockeys' and explained that:

...rather than taking ten minutes out to walk over and discuss that new information with someone, these guys constantly FYI emails around to everyone. That's not really transferring knowledge. These email jockeys are useless...nobody ever reads the emails they send around anyway.

Unlike the 'email jockeys', the internal stars are aware that an email containing new information will only be read if it is translated into a form that is relevant and understandable to the recipient. Rather than blasting out an email under the title FYI, they tend to include a short introduction on the email that explains/translates why the information contained is relevant to the receiver. External knowledge will not disseminate effectively in the group unless it is first translated into terms relevant to group members. It seems that the internal communication stars possess these translation skills and their emails gain the attentions of the intended recipients as a result. In contrast, the 'email jockeys' do not translate the information contained in their email messages, possibly because they do not have technical competence to perform the translation, and their messages are rarely read as a result.

Additionally, with so much information freely available on the Web, determining the reliability and validity of this information is an issue. The internal stars of the group are frequently sought out by their colleagues with these issues in mind. The following is a quote from an internal star whose specialty domain is quality management. She explains that it is very easy for other members of the group to acquire information from the Web, but before using that information, they consult with her to ensure that it is valid and reliable:

Some of the project managers do go off and look for quality information off the FDA websites...they are well capable of finding out that information themselves but they double check that they have done it correctly with me. So, they are capable of finding information themselves but they don't run with it until they have had the OK...Is this the way I should be doing this? Do you know of a better way of doing it? How did we do it previously? These are the types of questions they ask me.

External Knowledge Dissemination: The interviews explored how the internal stars and gatekeepers disseminate external knowledge around the group. Very little differences were discovered and the findings presented here are representative of both. The group has a very informal structure and knowledge flows quite easily around the group as a result. Email and faceto-face are the two media used to disseminate external knowledge. Which medium is used depends on the format of the information - digitized information (e.g. documents, Weblinks, powerpoint slides) is disseminated through email while oral-based sources are disseminated through face-to-face discussions. On a day-to-day basis, email would be the more frequent channel used. However, while email is used to alert colleagues to potentially useful knowledge, most of the interviewees felt that email was not suitable for having a detailed technical 
discussion. Email serves as the first step in distributing external knowledge around the group. If the receiver reads the email and feels that the information contained is relevant to them, the next step is to have a face-to-face discussion with the sender about that information and how it can be applied to the specific work of the group.

From our interpretation of the SNA evidence, we proposed that the external stars acquire novel external knowledge, which they then pass to the internal stars who disseminate that knowledge around the group. Support for this particular route was found in the interviews with the internal stars. One internal star acknowledged that certain colleagues send him useful external information which he in turn distributes around to others. Indeed, he was able to recall a specific example which happened the morning of the interview:

There are definitely people in here who would send me on something new that they came across. I would send out similar emails myself...I'm not sure how many each week, maybe 3 or 4 . Come to think of it, I did something like that this morning. I helped out one of John's guys a while back... a prototyping problem he was having. He sent me email this morning... a solid modeling video on YouTube. It's not really my area so I forwarded it to one of the guys who does solid modeling and just said 'have you seen this?'

The interviews also explored the abilities needed to disseminate. External knowledge will not be considered unless it is made relevant to the R\&D engineers in the group. To distribute information that is relevant to a recipient, the sender needs to know what the recipient's interests and expertise are to begin with. Even though this R\&D group is relatively small with 42 members, some of the interviewees indicated that they would have a poor grasp of the specific expertise of others, particularly those outside their immediate project team. In contrast to these views, the internal stars were confident that they had a good understanding of most people's skills base in the group. A variety of reasons were offered by the internal stars as to how they came to know the collective expertise within the group. These views are best summed up in the following quote from the internal star who also happens to be the most connected member of group. Through a combination of being very approachable and having recruited most of the group, he has a good idea of what others know:

I think it's because I'm very approachable and I actually enjoy helping others. And I quite like them coming to me. If someone comes to me and I don't really know the answer then I won't push, I'll say "to be honest I just don't know" but there's a good chance I know the person who can help. You see, I've been here from the beginning and myself and [the R\&D Manager] have interviewed most of the people here now. So I've seen people's CVs and I know what they have done in the past. So I know that certain people had molding experience or that certain people had worked with cements. I'd have a fair idea of where the knowledge sat so I'd always pick the person that you should be going after.

\section{DISCUSSION}

This paper asked the question "How have Web technologies impacted the technological gatekeeper's tasks of acquiring, translating, and disseminating external knowledge?" While we find that the gatekeeping tasks are integral to the R\&D operation, we also find that these tasks no 
longer need to be performed by a single individual. Gatekeepers do exist, but they are rare. When Allen (1977) first formulated the theory, the gatekeeping role could only be performed by a single individual because technical communications were predominately oral based. Among other skills, the traditional gatekeeper needed excellent social networking abilities in order to effectively acquire and disseminate knowledge orally. While other R\&D engineers may have wanted to perform the gatekeeping role, the lack of these social networking skills possibly impeded them. Combining the results of this study with the literature, an updated conceptual framework of the gatekeeper concept is illustrated in Figure 4. We acknowledge however that the framework is a simplistic representation of an extremely complex process.

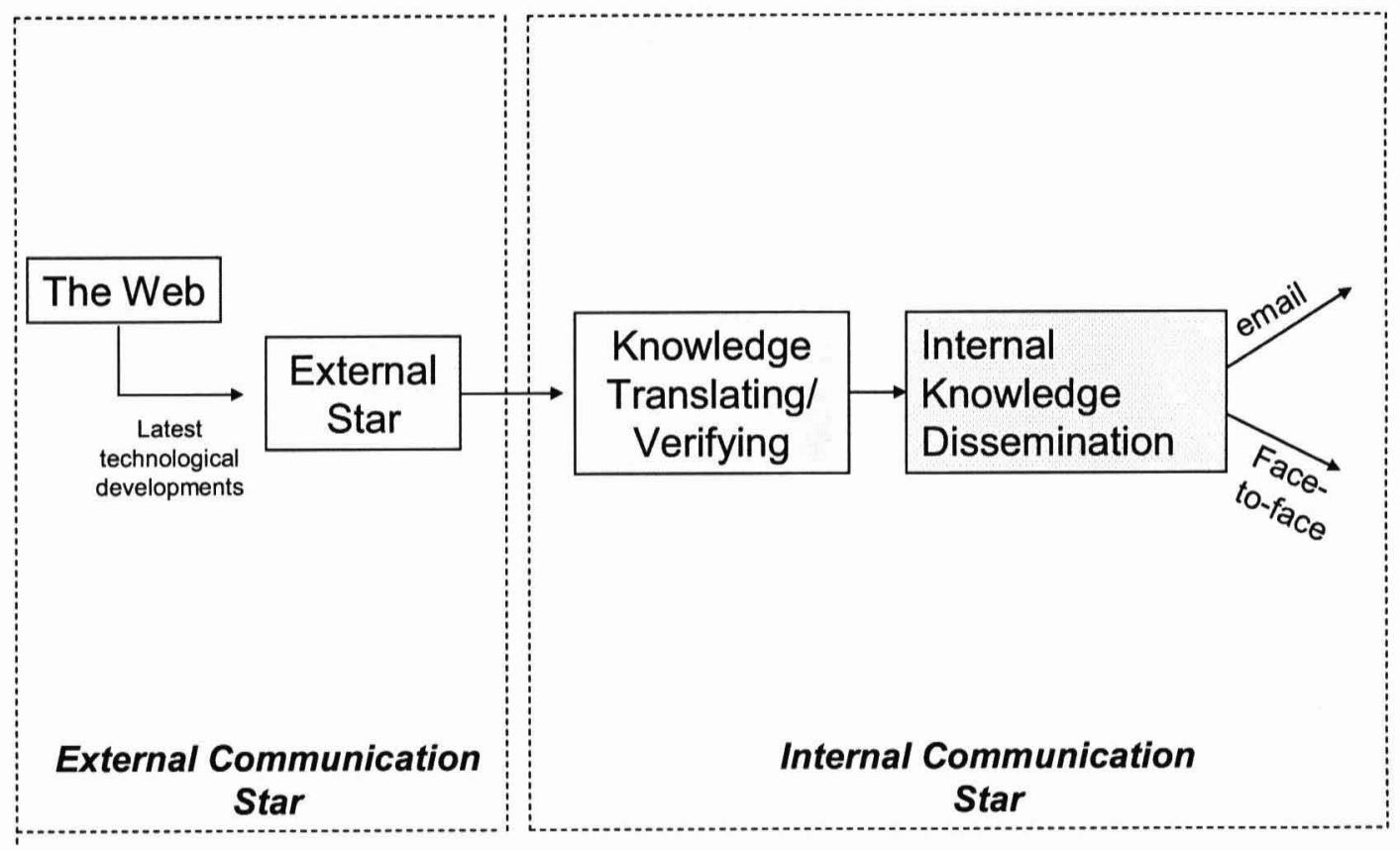

Figure 4: The Updated Gatekeeper Conceptual Framework

From the study of this R\&D group, we find that Web technologies now enable the individuals that are interested in external developments to easily access that knowledge. Rather than having social networking skills, these external communication stars possess analytical and Internet search skills. However, the lack of excellent social networking skills inhibits the ability of the external stars to distribute that knowledge around the group themselves. This is the domain of a different set if individuals, the internal communication stars, who possess the ability to effectively translate and disseminate external technical knowledge. The translation task has also been impacted by the prevalence of Web technologies. As much of the group's external knowledge is JITCAR Volume 11, Number 2, 2009 
now obtained from the Web, an integral step in the knowledge translation task is the validation of that information to be accurate and reliable. Many of the internal stars are consulted by their colleagues for this purpose yet knowledge validation is not discussed in the previous gatekeeper literature. Additionally, as email is the bedrock of the internal communication system, the internal star will usually write $2-3$ sentences translating the attached information into terms relevant to the recipient. Without this translation, the information attached in the email will not be read. Regarding knowledge dissemination, social networking skills still play an important role in the execution of this task. While email is the predominate channel used to alert colleagues to external developments, the sender needs to be familiar with the specific skills of his or her colleagues in order to direct that knowledge to those who are best placed to exploit it. This familiarity results from networking internally. Indeed, one could argue that through Darwinistic procedures, the traditional gatekeeper has evolved into an internal communication specialist, allowing others to specialize in gathering external knowledge. However, our evidence from this case study is insufficient to fully support such an assertion.

\section{CONCLUSION}

The findings of this paper are of benefit to both theory and practice. We contribute to the ITenabled social network literature by advancing the gatekeeper theory into the $21^{\text {st }}$ century. We show that the gatekeeper role has fragmented, enabling it to be performed by Web-enabled boundary spanners and internal communication specialists. This study should be of particular interest to R\&D managers. Practitioners are increasingly aware that innovative knowledge is located beyond the boundaries of their firm. This study finds that the Web is a vital tool for accessing this knowledge and that certain people exist who have the innate ability to find relevant knowledge on the Web. It will be increasingly important for R\&D firms to find people with the right blend of social and analytical skills. We have also identified some negative aspects to the Web-enabled R\&D group that managers will need to be aware of. Firstly, with so much information freely available on the Web, verifying the accuracy and reliability of this information is becoming a critical step in the knowledge integration process. Managers will need to ensure that proper verification procedures are in place. Secondly, an interesting finding was the existence of certain individuals who constantly send FYI emails to their R\&D colleagues. Rather than enhancing knowledge flows, the actions of these individuals are seen as a hindrance. The FYI phenomenon could become a significant problem if group members become overloaded with irrelevant messages and end up not reading the important messages.

We see two additional areas for future research. Firstly, while our findings make a unique contribution, they are based on only a single case study with a population of 42 members. For the purposes of generalizability, future research studies should examine multiple R\&D groups in differing industries with larger populations. Secondly, our findings show that the gatekeeping role can be performed by a single individual or by a combination of internal and external communication specialists. Future research needs to examine which of these routes is most effective for R\&D project performance. 


\section{REFERENCES}

1.Aldrich, H. E. \& D. Herker (1997). Boundary spanning roles and organization structure. Academy of Management Review, 2 (April), 217-230.

2. Allen, T. J. (1971). Communication networks in R\&D laboratories. R\&D Management, 1, 14-21.

3. Allen, T. J. (1977). Managing the Flow of Technology, Cambridge MA, MIT Press.

4.Allen, T. J. \& Cohen S.I. (1969). Information flow in research and development laboratories. Administrative Science Quarterly, 14(1), 12-19.

5. Allen, T. J., Tushman, M.L \& Lee, D.M.S. (1979). Technology transfer as a function of position in the spectrum from research through development to technical services. Academy of Management Journal, 22(4), 694-708.

6. Assimakopoulos, D. \& Yan, J(2006). Sources of knowledge acquisition for Chinese software engineers. $R \& D$ Management, 36(1), 97-106.

7.Assimakopoulos, D. \& S. Macdonald (2003). Personal networks and IT innovation in the Esprit program. Innovation Management, Policy and Practice, 5(1), 15-28.

8.Borgatti, S. P., Everett M.G. \& Freeman L.C. (2002). Ucinet for Windows: software for social network analysis. Harvard MA, Analytic Technologies.

9.Burt, R. S. (1992). Structural Holes: The Social Structure of Competition. Cambridge MA, Harvard Business Press.

10. Chesbrough, H. M. (2003). Open Innovation. Boston MA, Harvard Business School Press.

11. Cohen, W. \& Levinthal, D. (1990). Absorptive capacity: A new perspective on learning and innovation. Administration Science Quarterly, 35, 128-152.

12. De Meyer, A. (1985). The flow of technological innovation in an R\&D department. Research Policy, 14, 315-328.

13. Eisenhardt, K., M (1989). Building theories from case study research. Academy of Management Review, $14,532-550$.

14. Friedman, T. L. (2006). The World is Flat. New York, Penguin Books.

15. Gladwell, M. (2000). The Tipping Point. London, Little Brown.

16. Granovetter, M. (1973). The strength of weak ties. American Journal of Sociology 78(6), 1360-1380.

17. Hansen, M. T. (1999). The search-transfer problem: The role of weak ties in sharing knowledge across organizational subunits. Administration Science Quarterly, 44, 82-111.

18. Harada, T. (2003). Three steps in knowledge communication: the emergence of knowledge transformers. Research Policy, 32, 1737-1751.

19. Katz, R. \& Tushman, M.L. (1981). An investigation into the managerial roles and career paths of gatekeepers and project supervisors in a major R\&D facility. $R \& D$ Management, 11, 103-110.

20. Leonard-Barton, D. (1992). Core capabilities and core rigidities: a paradox in managing new product development. Strategic Management Journal, 17, 93-108.

21. Macdonald, S. \& Williams, C. (1994). The survival of the gatekeeper. Research Policy, 23, 123-132.

22. March, J. G. \& H. Simon (1958). Organizations. New York, Wiley.

23. Miles, M. B. and A. Huberman (1984). Qualitative data analysis. London, Sage.

24. Myers, M. D. \& M. Newman (2007). The qualitative interview in IS research: Examining the craft. Information and Organization, 17, 2-26.

25. Nochur, K. S. \& Allen, T.J. (1992). Do nominated boundary spanners become effective technological gatekeepers? IEEE Transactions on Engineering Management, 19(3), 265-269.

26. Parameswaran, M. \& Whinston, A.B. (2007). Research issues in social computing. Journal of the Association for Information Systems, 8(6), 336-350.

27. Rogers, E. M (1995). Diffusion of Innovations. New York, The Free Press.

28. Rogers, E. M. (1962). Diffusion of Innovations. New York, The Free Press. 
29. Su, N. M., Mark, G \& Sutton, S.A. (2007). Workplace connectors as facilitators for work. Paper presented at the 3rd International Conference on Communities and Technologies, Michigan, USA.

30. Teigland, R. \& Wasko, M. (2003). Integrating knowledge through information trading: examining the relationship between boundary spanning communication and individual performance. Decision Sciences, 34(2), 261-287.

31. Tushman, M. (1977). Special boundary roles in the innovation process. Administrative Science Quarterly, 22 (December), 587-605.

32. Tushman, M. \& Katz, R. (1980). External communication and project performance: an investigation into the role of gatekeepers. Management Science, 26(11), 1071-1085.

33. Tushman, M. \& Scanlan, T. (1981). Boundary spanning individuals: their role in information transfer and their antecedents. Academy of Management Journal, 24(2), 289-305.

34. Wasko, M. \& Faraj, S. (2005). Why should I share? Examining social capital and knowledge contribution in electronic networks of practice. MIS Quarterly, 29(1), 35-57.

35. Wasko, M., Faraj,S \& Teigland, R. (2004). Collective action and knowledge contribution in electronic networks of practice. Journal of the Association for Information Systems, 5(11-12), 493-513.

36. Wenger, E., McDermott, R. \& Synder W.W. (2002). Cultivating communities of practice. Boston, Harvard Business School Press.

37. Whelan, E. (2007). Exploring knowledge exchange in electronic networks of practice. Journal of Information Technology, 22, 5-13.

38. Whelan, E., Ahonen, M \& Donnellan, B. (2008). Knowledge diffusion in R\&D groups; the impact of Internet Technologies. Paper presented at the 16th European Conference on Information Systems, 2008, Galway, Ireland

39. Yin, R. K. (1994). Case Study Research; Design and Methods. London, Sage.

\section{APPENDIX}

\section{Sample of the Semi-Structured Interview Questions}

Questions directed to External Communication Stars and Gatekeepers

- Please describe your role in the R\&D group?

- Is it important for you to stay abreast of the emerging developments in your field? Why?

- How do you stay abreast of these emerging developments? Personal colleagues, ICT, journal papers etc.

- What are the key communication technologies you use to keep abreast of emerging developments?

- What are the differences between these external sources? In what situations would you use one source over another?

- What do you do with this acquired information? Use it yourself, share it with others?

\section{Questions directed to Internal Communication Stars and Gatekeepers}

- Are you frequently consulted by your R\&D colleagues? What is the nature of these consultations? What specific skills do you possess to deal with these consultations?

- How is knowledge of emerging technological developments disseminated around the group? What are the key communication technologies used in this process?

- Why do you share your knowledge with others? Where do you acquire this knowledge to begin with?

- Please describe a recent case where you shared useful technical knowledge with another in the group? 
Questions directed to non Communication Stars

- Is it important for you to stay abreast of the emerging developments in your field? Why?

- How do you stay abreast of these emerging developments? Personal colleagues, ICT, journal papers etc.

- Who are your 'go-to' people in the R\&D group? Why do you consult with these particular individuals? What attributes do they possess that others do not?

\section{ABOUT THE AUTHORS}

Eoin Whelan is a Lecturer in Information Management at the University of Limerick, Ireland. Before lecturing, Eoin had a variety of Business Analyst positions in Ireland, New Zealand, and the US.

Brian Donnellan is a Lecturer in Business Information Systems at the National University of Ireland Galway. Prior to becoming an academic, Brian spent 20 years working in Industry in roles associated with Innovation Systems development and support.

Willie Golden is a Professor in Information Systems at NUI Galway. He has co-authored a book, contributed 10 chapters to books and published 16 journal papers in the areas of Electronic Commerce and Information Systems. 